average stature, according to D'Orbigny, is 5 feet 3 inches, while the Yagans range from 4 feet Io inches to 5 feet 4 inches, and the women from 4 feet 9 inches to 5 feet. But in other respects they present a more debased appearance than their continental congeners, being distinguished by low brows, prominent zygomatic arches, large pendent lips, flat nose, round face, loose, wrinkly skin (" pelle grinzosa e cadente"), thin extremities, the legs curved outwards. The black hair is of the usual American texture, coarse, lank, and long, but in one district chestnut and wavy, due, no doubt, to mixture with white blood. ${ }^{1}$

They neither tattoo nor paint the body, which is exposed almost naked to the inclemency of an excessively rigorous and stormy climate. In this respect the Fuegians present a striking contrast to the Eskimo at the opposite extremity of the continent, the general cut of whose warm and comfortable attire may, according to Mr. E. B. Tylor, be due to the influence of the old Norse settlements in Greenland. Although Bove gives us two distinct terms, accar and tuma-chi for house and hut respectively, the dwellings themselves are all alike described as wretched hovels, made of branches stuck in the ground and loosely bound together in the Botocudo fashion. More skill and care is displayed in the construction of their beechwood canoes, which are generally from fifteen to twenty feet long and about two feet wide. In these frail craft they navigate the intricate channels of their sturm-swept waters, and boldly pursue the whale and dolphin often far out on the bigh seas beyond sight of land ("spesso fuori dalla vista d'ogni terra"). Here, however, it may be well to remember that similar statements were constantly made of the Andaman islanders until Mr. Mann recently showed that in their light outriggers they never venture far from the shore.

Like the Araucanians the Yagans are polygamists, and, like the followers of the Prophet, they have generally four wives. But, while the Araucanians purchase their mates, ${ }^{2}$ the Fuegian bride is provided with a dowry consisting usually of a canoe and a few harpoons. Nevertheless all the hard work, such as fishing, hutbuilding, the kindling and preservation of fire, falls to the share of the women, who in return meet with nothing but the most brutal treatment from their helpmates. "How often," writes Bove, "have I seen men seated cosily round a good fire, while the wretched women remained exposed to the snow, wind, water, fishing for their idle and unmannerly husbands!" Notwithstanding their hard lot the women are exceptionally fruitful ; but, on the other hand, a small percentage only of the children resist the severity of the climate. They leave the paternal roof at a very early age, and begin to shift for themselves before reaching their teens. In fact family ties can scarcely be said to exist, and the only affection of which the Fuegian seems capable is "self love." "How often," again remarks the Italian explorer, "have I seen the father devouring a hunch of meat or bread, while round him stood wives and children, their eyes riveted on the food, with features distorted by hunger, rendered all the more painful at sight of others being sated, timidly gathering the scraps dropping from his lips, and falling rabidly on the remnants of the feast contemptuously thrown to them by the ferocious head of the household!"

Each family circle lives apart in absolute independence, combining only in small tribal groups for the purpose of

1 With this description may be compared that of the fourteen Araucanians now encamped in the Jardin des Plantes, Paris, and figured in the Illustra. tion of July 28,1883 . The low brow, high cheek-bone, flat nose, lank hair, and general flat features give to both races a common Monguloid expression. and general is distinctly seen in the Guarani. Tupi, Botocudos, and so meny other South American peoples. This expression seems in fact almost more pronounced in the southern than in the northern races of the New World, and nounced in the southern than in the northern races of the New World, and it is certainly remarkable that the physical appearance of the Araucanians
and Fuegians should be even more suggestive of an Asiatic origin than is and Fuegians should be even more sugges
that of the Eskimo and Athabascan groups.

${ }_{2}$ "L'Araucanien peut prendre autant de femmes qu'il en peut nourrir et payer aux parents, car les femmes s'achètent. "- L'Illustration, July 28 . ז883. mutual defence against some common enemy. Thus it is that the first germs of the community are sown by the necessity of self-preservation, just as the fully organised society is still kept together by the same overruling principle. But in the Fuegian community the idea of headship has not yet been evolved. No one claims the right to assume the chieftaincy, or to meddle in the concerns of his neighbour. Hunting or warlike excursions are arranged by common consent, and the spoils of war or the chase are equally distributed amongst the members of the expedition. Certainly the Fuegian social system seems to favour the views of those, rather, who hold that everywhere the commonwealth preceded oligarchy and the monarchy. As the monotheistic conception was arrived at through pantheism and polytheism, so in the social order the autocrat appears as the final outcome of

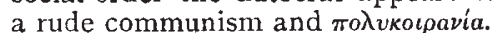

The Yagans, however, seem to have scarcely reached the pantheistic, or perhaps it would be more correct to say the pananthropomorphic, state. Religious notions, in the strict sense, cannot be said to exist where no clear distinction has yet been drawn between the natural and supernatural. Fven with superstitious ideas they are but little troubled ("sono pochissimo superstiziosi"), while their indifference to the remains of the dead would seem to imply that they have no anticipations of an after life. To the naturalists of the Italian expedition they freely parted with the crania of fathers, friends, and relations, without the least outward symptoms of regret. In one instance, however, a good deal of sentiment was expressed by a young Yagan, who thus somewhat poetically addressed the skull of his father: "Farewell, dear father. You, who when alive never saw aught but our snows and our storms, are now going dead far far away!" This is the language of one, in whom at least dim visions of another existence seem to be dawning.

Considering the extremely low state of their culture, it requires a considerable desree of credulity to accept the statement that their agglutinative language possesses some 30,000 words, besides highly complex and elevated grammatical forms ("ha circa 30,000 vocaboli, e forme grammaticali molto complesse e elevate"). This is naturally regarded as a sure proof that the Yagans have had a much higher origin than might appear from their present debased condition. But it will be safer to await further proof before accepting the statement at all. Reserve is the more needed that we are told somewhat mysteriousiy that this linguistic phenomenon was very little studied by the explorers ("femoneno notato, quantunque pochissimo studiato, dei nostri exploratori.") It is also curious that, with such a copious vocabulary, of which a few specimens are given, the same word yash should have to do duty both for hand and finger, as well as for head, this last, however, doubtless as a homophone, or else through one of those mistakes which cannot always be avoided even by careful students of barbarous languages. The numerals do not seem to get beyond five (cu-pash-pa, an obvious compound), which is again somewhat inconsistent with a vocabulary of 30,000 words! But we may soon expect further light to be thrown. upon this point by the English missionaries, who are doing such excellent work among the Yagans of Beagle Channel, and whose labours will doubtless soon be extended to the whole of the Fuegian Archipelago.

A. H. KEANE

\section{THE ISCHIAN EARTHQUAKE}

$T \mathrm{HE}$ report from the Central Observatory, by Prof. de Rossi of Rome, shows that signs of the coming catastrophe were not wanting at the different meteorological stations. What follows is, according to the Daily Nerws correspondent, the most interesting part of Prof. de Rossi's report.

"Several days before the $25^{\text {th }}$ and 28 th July the micro- 
cosmical instruments at Rocca di Papa and connected microphones in Rome showed a great increase in subterranean activity. The earthquake which took place at Cosenza and Catanzaro on July 25 seemed to be the one predicted by those movements; but their continuance and increasing force showed clearly the approach of a new dynamic effort. Science, however, cannot yet determine the topographical point menaced by such effort, because we have not a sufficient number of observatories, and they are especially wanting in the places where the manifestations of the subterranean forces are most to be feared. Thus we could only suspect the direction of the movement, and gather from the daily observations made here and there in Italy that the seismic activity has concentrated in the southern part of the peninsula. The earthquake of Saturday, July 28, was registered by the seismographs in Rome, Velletri, and Ceccano at 9.30 p.m., with slow waves from north to south and east to west. The other instruments, which register quick and abrupt movements of the ground, remained quiet. As far as can be gathered from the observations till now made, this earthquake was an exact but more extensive repetition of that of March 4, 188I, and those just preceding, confirming the previsions and data collected at that time. It is deplorable that my advice respecting the institution of regular observations in those parts was not followed, as such observations would certainly have given warning of the imminent catastrophe. I gave that advice not only immediately after the catastrophe of March 4, but also on my visit to Naples at the Meteorological Congress. In consequence of that visit I wrote in the name of the Observatory to the director of one of the chief baths in Ischia, begging him at least to un. dertake daily note of the temperature of the thermal waters and the state of the fumarole (natural apertures from which issue smoke and steam). Alteration in the temperature of thermal-mineral springs, when that alteration exceeds certain limits, is one of the surest signs of a subterranean storm, and such alteration has always been noticed at Casamicciola, even without regular scientific observations. This time, as often before, the drying up of wells, subterranean thunder, and slight oscillations of the earth, have preceded the catastrophe, which shows what valuable indications might have been afforded by the delicate seismic instruments, the microphones, and telephones now at our command. The reluctance shown to follow my advice arose purely from a selfish fear lest the establishment of a meteorological observatory at Casamicciola should give an appearance of danger, and frighten visitors away. This false idea is so prevalent in the minds of even educated persons in the place that notices of the occurrence of small phenomena during the last few years have often reached me with great reserve, and very late. Let us hope that such a prejudice will not long continue to the damage of science."

The actual moment of the explosion has, according to the correspondent of the Standard, been variously stated. The clock in the Sala Belliazzi stopped at twenty-two minutes past nine, but it is generally agreed that the real time was fifteen or twenty minutes later-a singular detail, which has not been generally noticed.

Shocks of earthquike are reported to have occurred daily in Ischia since the 28 th ult.

Prof. Palmieri states that all the later shocks felt at Ischia have been registered instantaneously by the seismographic instruments at the Observatory on Mount Vesuvius. On Friday morning, according to the Naples correspondent of the Standard, the instruments showed signs of considerable subterranean disturbance. Vesuvius was rather active, but the fear that a fresh crater was about to open immediately above Torre del Greco appears to be unfounded. Neapolitan passengers returning from Ischia appeared delighted to see Vesuvius blazing away in the distance. "Oh," said they, "so much the better; that may, perhaps, be a safety valve." Rossi and other observers, who differ from Palmieri on this point, predict nothing less than the reopening of the old crater of Monte Epomeo or the opening of a new one.

In making the tour of the hospitals on Wednesday, in order to collect the narratives of the wounded, the Standard correspondent found strong confirmation of the fact that there were signs of danger two or three days beforehand, which cannot have escaped the observation of the inhabitants of the island; but they were, unfortunately, he states, suppressed, in order to avoid giving alarm to the visitors, and so spoiling an unusually prosperous season. The Advocate Jeremiah Tonti, of Antria, Bari, who lies badly hurt in the Church of the Pellegrini, adjoining the great hospital, related to the correspondent that he had gone there with his wife to take the baths for rheumatism. The spring used comes forth from the ground so bot that it is necessary to temper it for the bath with one-fourth of cold water, but two days before the disaster the temperature of the spring rose so suddenly that it was found impossible to enter the bath until the supply of cold water had been largely increased. Dr. Dominico Bucco, who lies at the Hospital of the Pellegrini, says that the shocks at Forio and Lacco Ameno were vertical as well as undulatory, so that the floors of the houses fell in one upon another from garret to cellar, sometimes still leaving the outer walls starding. He was also conscious of a momentary whirling motion, as if being drawn into the vortex of a whirlpool.

A telegram from Athens states that a strong shock was felt at Piræus on Saturday last.

WE have received the following communication from Dr. Johnston-Lavis, of Naples:-

The island of Ischia is but too well known from the earliest historic times for the prevalence of earthquakes and even volcanic eruptions. In 1827 a shock destroyed the greater part of Casamicciola, some portion of Lacco Ameno, and injured Fontana Serrara, besides shaking severely Barano and Forio. On March 4, I $88 \mathrm{I}$, a quite similar shock to the former brought down a large number of houses and severely injured the rest. The present one occurred at about 9.30 on Saturday, July 28 , and resulted in the absolute and total destruction of the whole town, most of Lacco Ameno, and a large part of Forio, Fontana, and Barano.

One remarkable fact is that the exact detailed area has been similarly affected in each case, so that the description of the earthquake of 1827 by Covelli, that of I88I by myself, and the present would be much the same; the only difference being in intensity. The earliest killed under 50 people, the second 127, and the present will carry the number near a thousand. ${ }^{1}$ The large increase of the deaths of the present one is due to its occurrence at the culminant point of the bathing season, so that the hotels were crowded with visitors; and the hour also found many of the peasantry going to bed.

The earthquake of two years since only ruined the worse built houses, and fissured the better ones, which were replastered and patched, so that the present shock has reduced every one to a heap of stones and mortar.

The shock was estimated to have lasted fifteen seconds, but a number of inquiries I have made as to what different persons had done to escape, and how the time was occupied between the first and last sensation, and the distance traversed during the movement, makes me believe thirty seconds nearer the point; for instance, one man awoke, jumped out of bed, stumbled over some furniture, opened the door, descended a flight of twenty steps, and when in the courtyard below still felt the movement.

The sound is said to have resembled a report followed

$$
\text { Later information makes it near 5000.-ED. }
$$


by boob, boob -, boob - , boob _ _ boob___, boob , and so on.

In the short notice of the earthquake of March 4, I88 I, I pointed out that the centre of the mesoseismal area or seismic vertical was at Casamenella, which occupies the same relative position to Epomeo as do Montagnone, Mount Rotaro, Cremate, and many other lateral cones. Also that this earthquake belongs to that subterranean class of movements that precede the bursting forth of an eruption such as the Vesuvian shock of A.D. 63, and the series that gave warning for some years before of the appearance of Monte Nuovo.

Prof. Samuel Haughton and myself are still engaged on a memoir of the last earthquake, and so far as we have gone we have found the following interesting facts :-

I. That the area of injury is very small.

2. That the angle of emergence rapidly diminishes as we recede from the seismic vertical.

3. That the focus is therefore very near the surface.

4. That there is another seismic vertical at Fontana. This is probably explained by conduction along a column of trachyte which occupies the old vent of Epomeo, as Fontana lies in the very centre of the old crater.

Mallet pointed out that shallow foci must produce violent effects in limited areas, that transmission to a distance of the earth-wave diminishes rapidly-conditions we find well illustrated in the present case. This led Prof. Palmieri to believe that the shock of I881 was the result of the tumbling in of the clay caves near Casamicciola, and he again proposes a similar explanation, as for this one he had not noticed any movement of the seis mographs of Naples of Vesuvius. On the former occasion I pointed out in my letter at the time that such could not be the case, not even as the result of the imagined spaces excavated by the dissolving action of the mineral waters. The real truth seems to be the inelastic nature of the tufas, which vary much in density and dip in every imaginable direction, so that the earth-wave has two powerful retarding agencies at work-the absorption by an inelastic medium, and continual reflection and refraction from its irregular structure. If really a falling-in had occurred as the cause of the earthquake, we should expect some signs of it, but such is not the case ; there is not a true fissure in the locality, and no apparent changes of level. Nor can we conceive that the houses of Forio, four miles distant, would be shaken about the ears of their inhabitants; besides in this one, unlike the preceding shock, Naples felt the movement quite distinctly.

In addition to the destruction of the houses by the shock, fires have burst forth amongst the ruins, and two large landslips have swept down from the flanks of Epomeo, and converted gardens and vineyards into utter ruin.

In conclusion I would remark, as was done on a former occasion, that we must expect other shocks more violent in character, and that, as one follows the other, the interval of tranquillity will be less, until the final eruption bursts forth. What time such an occurrence may be expected it is only possible to judge by the force, character, and frequency of future events. Only last week I advised Dr. Dohrn of the peril of living at Casamicciola; and another friend, who would not heed my warning as to the event and the dangerous position of certain rooms in his house with regard to the seismic vertical, has lost his son in the part of the building indicated.

Would this not be a remarkably favourable occasion to carry out a thorough investigation of the whole of the phenomena accompanying this type of earthquake? If, for instance, some scientific society would choose a committee, provide a number of suitable seismographs to be placed in different parts of the island, and any other means that might be proposed, so as to study the progress of the focus towards the surface, if such is really the case, the form of the focal cavity, and many other points of interest, it might be the means of preventing further catastrophes by showing the nearing approach of volcanic matter to the surface.

The horrors of the occasion I will not touch upon, as it is the province of other newspapers, not to speak of the hurry in which I send off this rough memorandum of my visit to the island,

Naples, July 30

H. J. JOHNSTON-LAVIS

P.S.-Since writing the above, notices from Isernia in the Apennines announce a severe earthquake in that locality, besides others at Sorrento and in other parts of Italy. The three Ischian shocks were each accompanied by a period of seismic activity in Italy and other parts of Europe. Vesuvius is slightly more active.

August I.-Another slight shosk occurred at Casamicciola about 4 p.m., and another a little before I 2 p.m.

August 2.-At I2.30 another shock took place.

There has not yet been time to collect data which may throw light on the origin of the terrible catastrophe that visited Ischia on the 28 th of last month. As in the case of the previous earthquake on the island, one of the most striking features of this last calamity is its extremely local character. There does not appear to have been any simultaneous perceptible tremor at Naples, and Professor Palmieri's delicate seismometers on Vesuvius registered no sympathetic movement on that mountain. That the source of the shock at Ischia must have lain comparatively near the surface may be confidently inferred. Had it been more than a few hundred feet deep, the waves of such a shock would assuredly have been propagated to a considerable distance all round.

Various possible causes of earthquakes have been assigned, each of which may at different times and places be effective in the production of the phenomena, The sudden snap of large masses of rock under great strain may be the origin of the frequent earthquakes of mountain chains, such as those so constantly experienced along the line of the Alps. On a smaller scale similar results may arise on a line of dislocation, as is probably the case at Comrie in Scotland. In volcanic regions the earthquakes that usually precede and accompany volcanic eruptions have been plausibly attributed to the explosions of elastic vapours, and particularly of steam. Ischia lies in a volcanic district, and is itself of volcanic origin. But its earthquakes do not seem to be part of the active volcanic phenomena of the district. So far as information is yet available regarding the recent catastrophe, there appear to have been no concomitant volcanic manifestations, though there were active vents where they might certainly have been expected to show themselves. The only facts yet known that might indicate a connection between the Ischian earthquake and the vulcanicity of the Neapolitan district are the reported outflow of lava from Vesuvius on the 3ist, and the alleged increase in volume and temperature of the Ischian hot springs. As regards the descent of lava towards Torre del Greco on Tuesday of last week, it did not take place until three days after the calamity of the 28 th ult, and may have been entirely independent of it. Disturbance of the thermal springs of the locality could hardly fail to accompany so severe a shaking of the ground, from whatever source the concussion might arise.

So far as materials exist for forming a judgment on the subject, the recent earthquake at Ischia appears to have been caused by the sudden collapse of some subterranean cavern, situated not far below the surface in the Casamicciola district. Such caverns no doubt frequently exist underneath volcanic vents from which large masses of material have been emitted. It is well known to geologists that one of the final phases in the history of a volcano is the subsidence of the cone. This downward 
movement probably continues during a long period of time. It may be on the whole gradual and imperceptible; but if, from time to time, the roofs of the huge vesicles, whence lava and steam have escaped, should give way, though there may be no perceptible change of level at the surface, such shocks will be generated as to convulse the area with earthquakes. We may infer that the Ischian earthquakes, though not directly connerted with the present active volcanic phenomena of the district, are the result of the former extravasation of volcanic materials, and the consequent vesicular condition of the earth's crust at the locality. But we must await the careful collection of evidence before any positive conclusion on the subject can be embraced.

\section{THE NORWEGIAN NORTH-SEA EXPEDITION}

WITH the general work of the expedition sent out by the Norwegian Government in $1876-8$ for the investigation of the physical and biological conditions of the North Atlantic, our readers have already been made familiar by communications from Dr. Mohn during the progress of the expedition. We have, moreover, already noticed one or two of the five volumes containing some of the results of the expedition. When the series of publications connected with the expedition is complete, it will form one of the most important contributions to a knowledge of the deep sea hitherto published. The present article is concerned with vols, iv. and v. of the series, containing a historical account of the expedition, a description of the apparatus used, the astronomical, magnetic, geographical, and natural history observations.

The historical account by Capt. Wille, who was in command of the vessel, the Voringen, tells us that so long ago as I874 Professors Mohn and G. O. Sars memorialised the Norwegian Government on the importance of a thorough investigation of the North Atlantic. In the memorial we find an excellent summary of what had already been done by previous expeditions, and what might be accomplished by a new one. The Norwegian Government entered heartily into the proposal for an expedition, and after taking competent advice in the matter, resolved to agree to the prayer of the memorial, and appointed Capt. Wille to make the necessary preparations. Capt. Wille at once proceeded to England to confer with Sir George Nares, and to purchase apparatus. A suitable vessel, the Voringen, was purchased, and specially fitted and equipped for the work of the expedition; very brief and elastic instructions were issued for the general conduct of the expedition, while each member of the comprebensive sciertific staff was furnished with special instructions for guidance in his work. The liberal scale on which the expedition was organised has guided the Norwegian Government in the publication of the results. These are contained in a series of large quarto volumes, beautifully printed (in Norwegian and English), and abounding with maps, coloured illustrations, and engravings. These volumes are liberally distributed among institutions and individuals in all countries, wherever indeed they are likely to be of service to science. Such liberality in a comparatively poor Government like that of Norway is in marked contrast to the conduct of the Government of the wealthiest country in the world in respect of the Challenger publications.

The general scope of the expedition was ( 1 ) to determine by soundings the contour of the sea-bed; $(2)$ the rate and direction of currents; (3) the surface-temperature of the sea; (4) to investigate the physical conditions and chemical constituents of the sea-water ; $(5)$ zoological work; (6) botanical work; (7) meteorological observations; (8) magnetical observations ; (9) whatever other observations time and place might render practical. Thus it will be seen the programme was comprehensive enough; and as the voluminous reports show, much valuable work was done in each department. Among the scientific staff on board were Prof. Mohn and G. O. Sars.

The Voringen prosecuted her work for about three months in the summers of the years $1876-7-8$. During
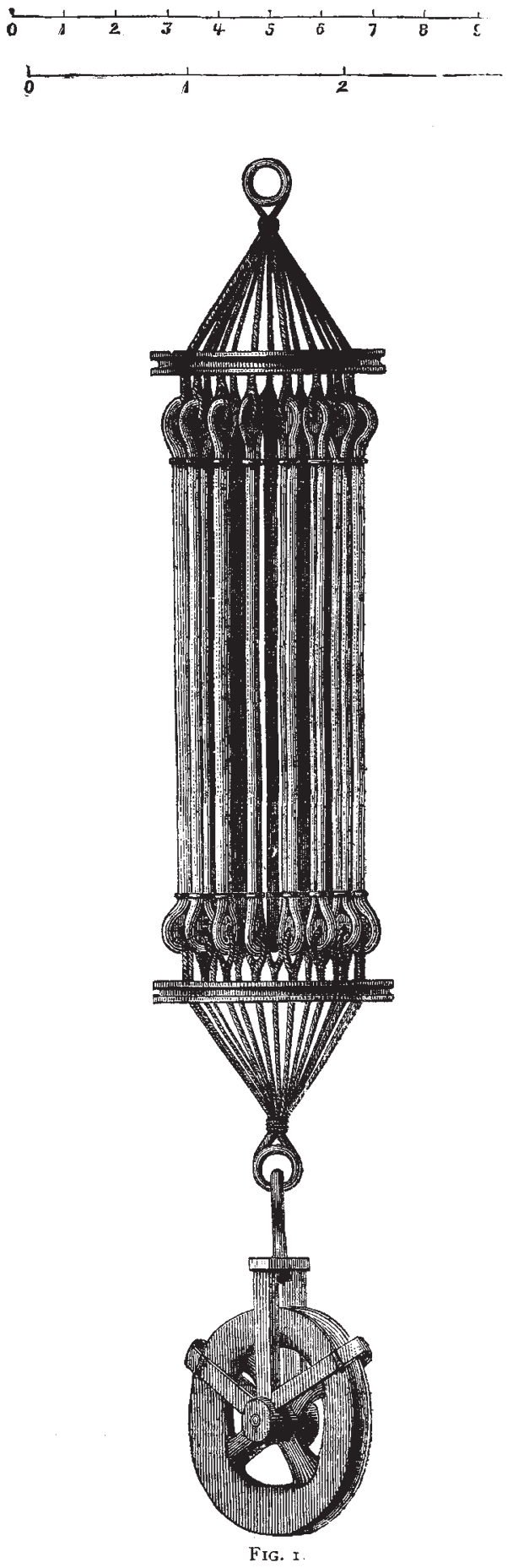

that time she made numerous sections over the region lying between the west coast of Norway and a line extending from Iceland to Spitzwergen on the one side, and between Faeroe and the north of Spitzbergen on the other; in 1878 moreover she made a circuit east and 